\title{
Acute Prosocial Effects of Oxytocin and Vasopressin When Given Alone or in Combination with 3,4-Methylenedioxymethamphetamine in Rats: Involvement of the $\mathrm{VI}_{\mathrm{A}}$ Receptor
}

\author{
Linnet Ramos', Callum Hicks', Richard Kevin', Alex Caminer', Rajeshwar Narlawar², Michael Kassiou ${ }^{2,3,4}$ \\ and lain S McGregor*, I
}

'School of Psychology, University of Sydney, Sydney, NSW, Australia; ${ }^{2}$ School of Chemistry, University of Sydney, Sydney, NSW, Australia; ${ }^{3}$ Brain and Mind Research Institute, University of Sydney, Sydney, NSW, Australia; ${ }^{4}$ Discipline of Medical Radiation Sciences, University of Sydney, Sydney, NSW, Australia

\begin{abstract}
The neuropeptides oxytocin (OT) and vasopressin (AVP) are recognized for their modulation of social processes in humans when delivered peripherally. However, there is surprisingly little evidence for acute social effects of peripherally administered OT or AVP in animal models. On the other hand, the party drug 3,4-methylenedioxymethamphetamine (MDMA, 'Ecstasy') has powerful prosocial effects in rats that appear to occur through stimulation of central OT release. Here, we directly compared the social effects of peripherally administered OT and AVP with those of MDMA, and examined a possible role for the vasopressin IA receptor $\left(V I_{A} R\right)$ in the observed prosocial effects. Adult male Long-Evans rats were tested in a social interaction paradigm after OT $(0.1,0.25,0.5$, and I $\mathrm{mg} / \mathrm{kg}$, intraperitoneal (IP)), AVP (0.00I, 0.0025, 0.005, 0.0 I, and $0.1 \mathrm{mg} / \mathrm{kg}, \mathrm{IP})$, and MDMA (2.5, $5 \mathrm{mg} / \mathrm{kg}, \mathrm{IP})$, or combined low doses of OT and MDMA, or AVP and MDMA. The effects of pretreatment with the non-peptide OT receptor antagonist compound 25 $(C 25 ; 5 \mathrm{mg} / \mathrm{kg}, \mathrm{IP})$ and the $\mathrm{VI} \mathrm{I}_{\mathrm{A}} R$ antagonist SR49059 (I mg/ $\left./ \mathrm{kg}, \mathrm{IP}\right)$ were also examined. OT $(0.5 \mathrm{mg} / \mathrm{kg})$, AVP $(0.0 \mathrm{I} \mathrm{mg} / \mathrm{kg})$, and MDMA $(5 \mathrm{mg} / \mathrm{kg})$ potently increased 'adjacent lying', where rats meeting for the first time lie passively next to each other. C25 did not inhibit adjacent lying induced by OT, whereas SR49059 inhibited adjacent lying induced by MDMA $(5 \mathrm{mg} / \mathrm{kg})$, OT $(0.5 \mathrm{mg} / \mathrm{kg})$, and AVP $(0.01 \mathrm{mg} / \mathrm{kg})$. Interestingly, when ineffective doses of OT and MDMA, or AVP and MDMA, were combined, a robust increase in adjacent lying was observed. These results show for the first time acute prosocial effects of peripherally injected OT and AVP in laboratory rats, and suggest a commonality of action of OT, AVP, and MDMA in stimulating social behavior that involves $\mathrm{VI}{ }_{\mathrm{A}} \mathrm{Rs}$.

Neuropsychopharmacology (2013) 38, 2249-2259; doi:I0.1038/npp.20I3.125; published online 12 June 2013
\end{abstract}

Keywords: oxytocin; MDMA; SR49059; social interaction; vasopressin IA receptor; adjacent lying; vasopressin; compound 25

\section{INTRODUCTION}

Oxytocin (OT) and vasopressin (AVP) are neuropeptides of considerable current interest because of their demonstrated capacity to modulate social behavior in humans and other animals (Caldwell et al, 2008; Lee et al, 2009). Owing to poor blood-brain barrier (BBB) permeability, they are usually given intranasally to humans (Domes et al, 2007; Kosfeld et al, 2005) or via direct intracranial injection or subcutaneous administration in animal studies (Insel and Winslow, 1991; Lukas et al, 2011; Witt et al, 1992). Intranasal OT in humans can increase trust, social risk taking, and social perception (Baumgartner et al, 2008;

*Correspondence: Professor IS McGregor, School of Psychology, University of Sydney, A I8, Sydney, NSW, Australia, Tel: +61 02935 I 357I, Fax: +61 029351 8023, E-mail: iain.mcgregor@sydney.edu.au Received 17 December 2012; revised I May 2013; accepted 6 May 20।3; accepted article preview online 16 May 2013
Domes et al, 2007; Kosfeld et al, 2005), while repeated dosing may benefit patients with schizophrenia (Feifel et al, 2012), autism (Hollander et al, 2007; Tachibana et al, 2013), and social anxiety disorder (Guastella et al, 2009). AVP on the other hand, improves memory (Perras et al, 1997; Pietrowsky et al, 1996), influences aggression (Thompson et al, 2004), and increases anxiety (Thompson et al, 2006) in humans.

In rodent studies, OT delivered repeatedly through an intracerebroventricular (ICV) route increases social interaction in male rats (Witt et al, 1992), and single-ICV administration reverses the social avoidance seen in rats subjected to social defeat or other stressors (Lukas et al, 2011). Despite the association between AVP and aggression and anxiety, there is also evidence for positive social effects of this peptide. Studies in prairie voles show that ICV infusion of AVP in males promotes a partner preference before meeting, and that OT administration has the same effect in females (Lukas and Neumann, 2012). Region- 
specific central administration of AVP also enhances social memory (Dantzer et al, 1988) and improves social recognition in rats (Veenema et al, 2011) and mice (Bielsky et al, 2005). Furthermore, intraseptal infusion of arginine vasotocin (the non-mammalian equivalent of AVP) promotes gregariousness and larger flock sizes in Zebra Finches (Kelly et al, 2011).

However, there is relatively little evidence of acute prosocial effects of peripherally administered OT (Hicks et al, 2012) or AVP (Appenrodt et al, 1998). In a recent study from our own laboratory, peripheral OT given repeatedly during adolescence produced lasting increases in sociability and decreased anxiety measured in adulthood (Bowen et al, 2011). Therefore, we decided to further examine here, whether acute prosocial effects of peripheral $\mathrm{OT}$, and perhaps AVP, might also be observed in rats.

The drug 3,4-methylenedioxymethamphetamine (MDMA, (Ecstasy') is a popular entactogen with well-documented prosocial effects in humans and laboratory animals. People commonly describe MDMA as causing an increased feeling of closeness to others, accompanied by a desire to interact socially, as well as euphoria, extraversion, enhanced tactile pleasure and a sense of peacefulness (Dumont and Verkes, 2006). MDMA increases social interaction in rats meeting for the first time, eliciting a characteristic behavior called 'adjacent lying', where rats lie together in close contact (Ando et al, 2006; Thompson et al, 2009). A similar behavior to adjacent lying, passive contact, has been previously described by File (1980) and others (File and Pope, 1974; Humphreys and Einon, 1981; Renner and Rosenzweig, 2004) and is believed to reflect an innate motivation towards tactile contact in rats (File and Pope, 1974; Latane et al, 1970), a motivation that MDMA likely increases. MDMA also decreases anogenital sniffing during social interaction. Rodents typically sniff the anogenital regions of conspecifics to decode identity, and the reduction of this behavior by MDMA might imply increased comfort and familiarity in the presence of strangers. Indeed, mice and fish demonstrate decreased aggression towards novel conspecifics when given MDMA (Capurro et al, 1997; Maldonado and Navarro, 2001).

The prosocial effects of MDMA have been linked to central OT release through both rat and human studies. MDMA acutely increases plasma levels of OT (Dumont et al, 2009; Thompson et al, 2007), and this increase correlates with increased subjective feelings of sociability in humans (Dumont et al, 2009). Furthermore, MDMA activates hypothalamic OT-containing neurons via an action on 5- $\mathrm{HT}_{1 \mathrm{~A}}$ receptors (Hunt et al, 2011; Thompson et al, 2007). In one study, the prosocial effects of MDMA were partly prevented by intracerebroventricular administration of the relatively non-selective OT antagonist tocinoic acid (Thompson et al, 2007).

It is known that MDMA also stimulates hypothalamic AVP release (Henry et al, 1998), and increases plasma levels of AVP and copeptin, a marker of AVP secretion (Simmler et al, 2011). However, the possible role of the AVP system in MDMA-induced social effects has not been addressed. AVP systems have an increasingly well-documented role in regulating sociability in many species (Engelmann et al, 2006; Lukas and Neumann, 2012), and OT itself has a moderate to strong affinity for vasopressin $1 \mathrm{~A}\left(\mathrm{~V} 1_{\mathrm{A}} \mathrm{R}\right)$ receptors (Hicks et al, 2012; Manning et al, 2008). Importantly, mice lacking OT receptors (OTR) display 'autistic-like' social deficits and impaired cognitive flexibility, and these are rescued via treatment with intracranial $\mathrm{OT}$, an effect likely mediated by the $\mathrm{V} 1_{\mathrm{A}} \mathrm{R}$ (Sala et al, 2011). On the other hand, $\mathrm{V} 1_{\mathrm{A}} \mathrm{R}$ knockout mice show impaired social interaction (Egashira et al, 2007) and social recognition (Bielsky et al, 2004). Moreover, peripheral tissue contractions, analgesia and proconvulsive effects induced by OT are prevented by pretreatment with SR49059 (Loyens et al, 2011; Schorscher-Petcu et al, 2010), a potent and selective $\mathrm{V} 1{ }_{\mathrm{A}} \mathrm{R}$ antagonist with efficacy at human and rat receptors (Manning et al, 2012; Schorscher-Petcu et al, 2010).

The present study examined whether peripherally administered OT and AVP could produce acute prosocial effects in laboratory rats, and the extent to which these resembled those seen with MDMA. A social interaction test was used, which assessed the interaction of two unfamiliar male rats meeting for the first time (File, 1980). There can be substantial differences in sociability between different rat strains (Rex et al, 1996), and our initial pilot work suggested that Long-Evans strain rats were particularly likely to display OT-induced social effects. To explore a mechanism for OT and AVP-facilitated social behavior, we investigated the antagonistic effects of compound 25 (C25), a nonpeptide OTR antagonist (Brown et al, 2010), and SR49059, a non-peptide $\mathrm{V} 1_{\mathrm{A}} \mathrm{R}$ antagonist, on observed prosocial effects. Finally, to gain further evidence of a common mechanism of sociability, we examined whether low doses of a combination of these drugs (OT and MDMA, or AVP and MDMA), that were ineffective in stimulating social behavior when administered alone, had prosocial effects when given in combination.

\section{MATERIALS AND METHODS}

\section{Animals}

Tests were conducted on experimentally naïve adult male Long-Evans rats (250-300 g) purchased from Adelaide University (Adelaide, SA, Australia). Rats were housed in groups of eight in large plastic tubs $\left(640 \times 400 \times 220 \mathrm{~mm}^{3}\right)$ in a temperature $\left(21 \pm 1^{\circ} \mathrm{C}\right)$ controlled colony room and maintained under a reverse $12: 12 \mathrm{~h}$ light-dark cycle (lights off at 0900 hours). Animals had ad libitum access to food and water except during testing. Rats were handled daily for $5 \mathrm{~min}$ for 7 days before testing. All experiments were conducted in accordance with the Australian Code of Practice for the Care and Use of Animals for Scientific Purposes (7th Edn, 2004) under the approval of The University of Sydney Animal Ethics Committee.

\section{Drugs and Drug Preparation}

OT and AVP were purchased from AusPep Ltd (Parkville, VIC, Australia) and dissolved in physiological saline (0.9\%) to produce various doses (OT: $0.1,0.25,0.5$, and $1 \mathrm{mg} / \mathrm{kg}$; AVP: $0.001,0.0025,0.005,0.01$, and $0.1 \mathrm{mg} / \mathrm{kg}$ ). MDMA was obtained from the Australian Government Analytical Laboratories (Pymble, NSW, Australia) and dissolved in saline to a dose of 2.5 and $5 \mathrm{mg} / \mathrm{kg}$. The OTR antagonist C25 
was synthesized in accordance with the methods of Brown et al, (2010) and was considered to be of $>95 \%$ purity based on proton, carbon nuclear magnetic resonance spectroscopy and mass spectrometry. It was dissolved in a $15 \%$ dimethyl sulfoxide (DMSO), 2\% Tween-80 and $83 \%$ saline vehicle at a dose of $5 \mathrm{mg} / \mathrm{kg}$. The $\mathrm{V} 1_{\mathrm{A}} \mathrm{R}$ antagonist SR49059 (Axon MedChem BV, The Netherlands) was dissolved to a dose of $1 \mathrm{mg} / \mathrm{kg}$ in the same vehicle used for C25. All drugs were administered to rats via intraperitoneal (IP) injection at a volume of $1 \mathrm{ml} / \mathrm{kg}$.

\section{Social Interaction Test}

Rats were tested in black, rectangular arenas $(780 \times$ $\left.520 \times 470 \mathrm{~mm}^{3}\right)$ dimly lit with red light $(80 \mathrm{~W})$ and lined with recycled paper bedding pellets (Breeders Choice, Toowoomba, QLD, Australia). Each arena was equipped with a miniature infrared video camera placed vertically over the center of the arena, which sent images to a computer outside the room that allowed test sessions to be recorded. Test sessions were manually scored by an observer blind to treatment conditions using the program ODLog (Macropod Software; www.macropodsoftware.com).

The behaviors of interest were (1) adjacent lying: side-byside contact, but not including climbing over or under the conspecific; (2) general investigation: sniffing of the conspecific, but not of the anogenital area; (3) anogenital sniffing: sniffing of the anogenital region of the conspecific; and (4) rearing: standing on hind legs, including leaning against the wall of the arena. Arenas were cleaned of fecal boli and the walls were sprayed with a $50 \%$ ethanol solution between each test session. Experiments lasted for $30 \mathrm{~min}$, unless otherwise noted, and were performed in the dark phase at an ambient temperature of $23^{\circ} \mathrm{C}( \pm 0.5)$.

\section{Experimental Procedures}

For all experiments, rats were individually habituated to the arena in which they would be tested for $60 \mathrm{~min}$ on the day before testing. Subjects were weight paired $( \pm 10 \mathrm{~g})$ with an unfamiliar conspecific given the same drug treatment that was randomly allocated. On test days, animals were individually placed in plastic holding cages $(470 \times 280 \times 180$ $\mathrm{mm}^{3}$ lined with the same recycled paper bedding used in the test arenas) in the testing room before, and between injections. Experiments involving MDMA used a betweengroups design where MDMA-treated rats only received the drug once. This was done to avoid possible downregulation of MDMA social effects with repeated exposure to the drug (Thompson et al, 2008).

\section{Prosocial Effects of OT (Experiment 1)}

The first experiment characterized the dose-dependent effects of OT on social interaction in male Long-Evans rats. Rats ( $N=8$ pairs) were tested with each of three doses of OT $(0.1,0.5$, and $1 \mathrm{mg} / \mathrm{kg})$ and saline in a counterbalanced order with two washout days between each of the four treatments. For each of the four tests, each rat was paired with a new partner relative to the previous sessions. Rats were placed in the test arenas for $30 \mathrm{~min}, 10 \mathrm{~min}$ after injection of OT.
Effects of C25 on OT-Induced Social Behavior (Experiment 2)

As a result of pilot work in our laboratory, we chose to give C25 at a dose of $5 \mathrm{mg} / \mathrm{kg}$ (IP) rather than the $2 \mathrm{mg} / \mathrm{kg}$ intravenous dose used to measure bioavailability by Brown et al (2010). In a between-groups design, pairs of rats $(N=6$ per condition) were administered either (1) vehicle + vehicle, (2) C25 (5 mg/kg) + vehicle, (3) vehicle + OT $(0.5 \mathrm{mg} / \mathrm{kg})$, or (4) C25 (5 mg/kg) + OT ( $0.5 \mathrm{mg} / \mathrm{kg})$. Injections were given $15 \mathrm{~min}$ apart and rats were tested for social interaction for $30 \mathrm{~min}, 10 \mathrm{~min}$ after the second injection.

\section{Effects of SR49059 on OT-Induced Social Behavior (Experiment 3)}

In a between-groups design, pairs of rats $(N=4$ per condition) were administered either (1) vehicle + vehicle, (2) SR49059 (1 mg/kg) + vehicle, (3) vehicle + OT $(0.5 \mathrm{mg} / \mathrm{kg})$, or (4) SR49059 (1 mg/kg) + OT $(0.5 \mathrm{mg} / \mathrm{kg})$. Antagonist/vehicle injections were given $15 \mathrm{~min}$ before OT/ vehicle treatment, and rats were tested for social interaction for $30 \mathrm{~min}, 10 \mathrm{~min}$ after the second injection.

\section{Prosocial Effects of AVP (Experiment 4)}

Rats ( $N=10$ pairs) were tested with each of four doses of $\operatorname{AVP}(0.001,0.005,0.01$ and $0.1 \mathrm{mg} / \mathrm{kg})$ and saline in a counterbalanced order with two washout days between each of the five treatments. For each of the tests, each rat was paired with a different partner relative to the previous sessions. Ten min after injection of AVP, rats were placed in the test arenas for $30 \mathrm{~min}$.

\section{Effects of SR49059 on AVP-Induced Social Behavior (Experiment 5)}

Using a between-groups design, pairs of rats $(N=4$ per condition) were administered either (1) vehicle + vehicle, (2) SR49059 (1 mg/kg) + vehicle, (3) vehicle + AVP (0.01 mg/kg), or (4) SR49059 (1 mg/kg) + AVP (0.01 mg/kg). Injections were given $15 \mathrm{~min}$ apart and rats were tested for social interaction for $30 \mathrm{~min}, 10 \mathrm{~min}$ after the second injection.

\section{Prosocial Effects of MDMA (Experiment 6)}

In a between-groups design, pairs of rats $(N=8$ per condition) were given either MDMA ( $5 \mathrm{mg} / \mathrm{kg}$ ) or saline, and $20 \mathrm{~min}$ later placed in the test arenas. Following on from our earlier studies with MDMA (Thompson et al, 2007; Thompson et al, 2009), this social interaction test was only of $10 \mathrm{~min}$ duration and was intended to show that our earlier results demonstrating prosocial effects of MDMA in Wistar rats could be replicated in Long-Evans rats.

\section{Effects of SR49059 on MDMA-Induced Social Behavior (Experiment 7)}

Using a between-groups design, pairs of rats $(N=8$ per condition) received injections of vehicle or SR49059 $(1 \mathrm{mg} / \mathrm{kg})$ followed $15 \mathrm{~min}$ later by MDMA $(5 \mathrm{mg} / \mathrm{kg})$. 
Testing commenced 20 min after the MDMA treatment and lasted for $30 \mathrm{~min}$. To minimize the number of rats used, this experiment did not include the vehicle + vehicle or SR49059 + vehicle conditions that had already been studied in Experiment 2.

\section{Prosocial Effects of Combined Sub-Threshold Doses of} OT and MDMA (Experiment 8)

In a between-groups design, pairs of rats $(N=4$ per condition) were randomly allocated to one of four conditions: (1) saline + saline, (2) saline $+\mathrm{OT}$, (3) saline + MDMA, and (4) OT + MDMA. A $0.25 \mathrm{mg} / \mathrm{kg}$ dose of OT and $2.5 \mathrm{mg} / \mathrm{kg}$ dose of MDMA were used as they are below the threshold of affecting social interaction. Drug injections were separated by $10 \mathrm{~min}$, and the $30 \mathrm{~min}$ test commenced 10 min after the second injection.

\section{Prosocial Effects of Combined Sub-threshold Doses of AVP and MDMA (Experiment 9)}

Using a between-groups design, pairs of rats $(N=4$ per condition) were randomly assigned to one of four conditions: (1) saline + saline, (2) saline + AVP, (3) saline + MDMA, and (4) AVP + MDMA. Sub-threshold doses of AVP $(0.0025 \mathrm{mg} / \mathrm{kg})$ and MDMA $(2.5 \mathrm{mg} / \mathrm{kg})$ were used. Injections were administered $10 \mathrm{~min}$ apart, and the $30 \mathrm{~min}$ test began $10 \mathrm{~min}$ after the second injection.

\section{Statistical Analysis}

Experiments 1 and 4 used a counterbalanced design where each rat received all possible doses of OT and AVP, respectively. As each data point represented a novel pairing of two rats, a between-subjects analysis was used to compare doses. In the remaining experiments, each rat received only a single treatment, so again a betweensubjects analysis was used. With the exception of Experiments 6 and 7, data were analyzed using the one-way ANOVA procedure followed by post-hoc tests (Tukey's) to enable specific group comparisons. Normality and homogeneity of variance (Levene's test) were checked and where these requirements were not satisfied, a $\log _{10}(X+1)$ or square-root transformation was applied to the data and the most effective correction was used for analysis. In the case where these assumptions could not be satisfied, the Kruskal-Wallis non-parametric test was used followed by the Games-Howell multiple comparisons test. Data from Experiments 6 and 7 were analyzed using the independentsamples $t$-test owing to their two group design. All analyses were conducted using SPSS version 19 (SPSS., IBM, Chicago, IL), with significance set at $P<0.05$ and only untransformed data are presented in the figures.

\section{RESULTS}

\section{Dose-Dependent Effects of OT on Social Interaction}

The effects of OT in the social interaction test is presented in Figure 1. OT had a significant overall effect on adjacent lying $(\mathrm{F}(3,28)=15.62, P<0.001$; Figure 1a), with post-hoc tests indicating that the $0.5 \mathrm{mg} / \mathrm{kg}$ dose significantly
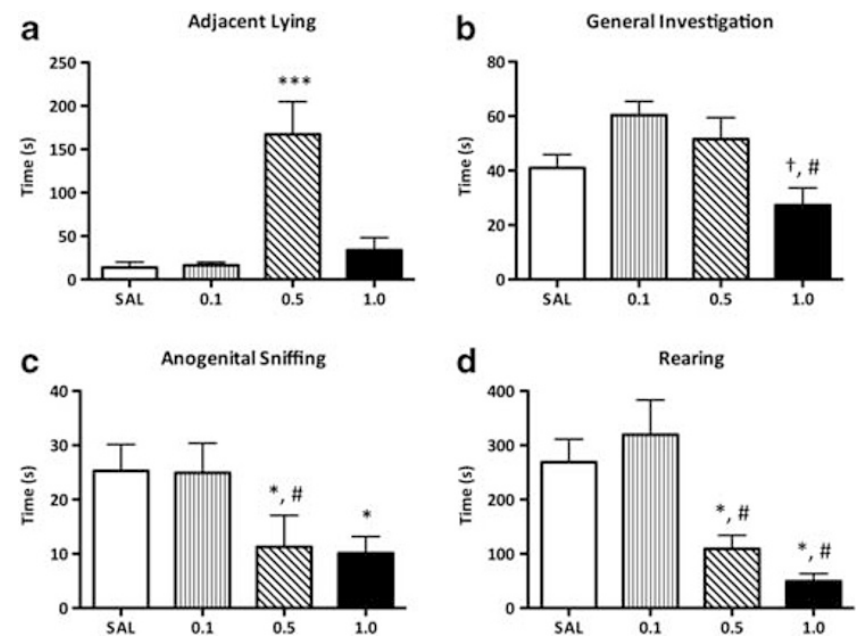

Figure I Dose-dependent effects of oxytocin (OT) on social interaction. (a) Rats given $0.5 \mathrm{mg} / \mathrm{kg}$ OT displayed increased adjacent lying. (b) A high dose of OT ( $\mathrm{Img} / \mathrm{kg}$ ) resulted in decreased general investigation when compared with 0.1 and $0.5 \mathrm{mg} / \mathrm{kg}$. (c) OT given at 0.5 and $1 \mathrm{mg} / \mathrm{kg}$ reduced anogenital sniffing compared with saline (SAL). The non-social behavior of rearing (d) was significantly reduced in rats given OT at 0.5 and I mg/kg compared with saline. Data are means $+\mathrm{SEM}$, ${ }^{*} P<0.05$ vs saline, ${ }^{\dagger} P<0.05$ vs $0.5 \mathrm{mg} / \mathrm{kg}$ OT, ${ }^{\#} P<.05$ vs $0.1 \mathrm{mg} / \mathrm{kg} O \mathrm{OT}$, ***** $P \leqslant 0.00$ I vs all other conditions.

increased adjacent lying compared with all other conditions (all $P \leqslant 0.001$ ) (see Supplementary Video). There was a significant effect of OT on general investigation $(\mathrm{F}(3,28)=5.38, P<0.01$; Figure $1 \mathrm{~b})$, with $1 \mathrm{mg} / \mathrm{kg}$ reducing the amount of investigation time relative to the 0.1 $(P<0.01)$ and $0.5 \mathrm{mg} / \mathrm{kg}$ doses $(P<0.05)$. Anogenital sniffing was also affected by OT $(\mathrm{F}(3,28)=5.14, P<0.01$; Figure $1 \mathrm{c}$ ), with $0.5 \mathrm{mg} / \mathrm{kg}$ reducing sniffing compared with saline treatment $(P<0.05)$ and $0.1 \mathrm{mg} / \mathrm{kg} \quad(P<0.05)$, while $1 \mathrm{mg} / \mathrm{kg}$ OT also reduced this behavior relative to saline $(P<0.05)$. OT also affected rearing behavior $(\mathrm{F}(3,28)=12.28, P<0.001$; Figure $1 \mathrm{~d})$, with post-hoc tests indicating that 0.5 and $1 \mathrm{mg} / \mathrm{kg} \mathrm{OT}$ attenuated rearing in comparison with saline $(P<0.05$ and 0.001 , respectively) and $0.1 \mathrm{mg} / \mathrm{kg}$ OT $(P<0.01$ and 0.001 , respectively).

\section{Effects of C25 on OT-Induced Social Behavior}

The effects of C25 on OT-induced social interaction are presented in Figure 2. There was a significant overall effect of treatment on adjacent lying $(\mathrm{F}(3,20)=18.68, P<0.001$; Figure 2a), anogenital sniffing $(\mathrm{F}(3,20)=18.57, P<0.001$; Figure $2 \mathrm{c})$, and rearing $(\mathrm{F}(3,20)=3.60, P<0.05$; Figure $2 \mathrm{~d})$. Post-hoc tests showed that OT given alone, and following pretreatment with C25, significantly increased adjacent lying and reduced anogenital sniffing and rearing, when compared with vehicle treatment and C25 alone (adjacent lying: all $P<0.01$; anogenital sniffing: all $P<0.001$; rearing: $P<0.05$ compared with $\mathrm{C} 25+$ vehicle). There was no significant effect of treatment on general investigation $(P>0.05$; Figure $2 \mathrm{~b})$.

\section{Effects of SR49059 on OT-Induced Social Behavior}

The effects of SR49059 on OT-induced social interaction are presented in Figure 3. There was a significant overall effect 

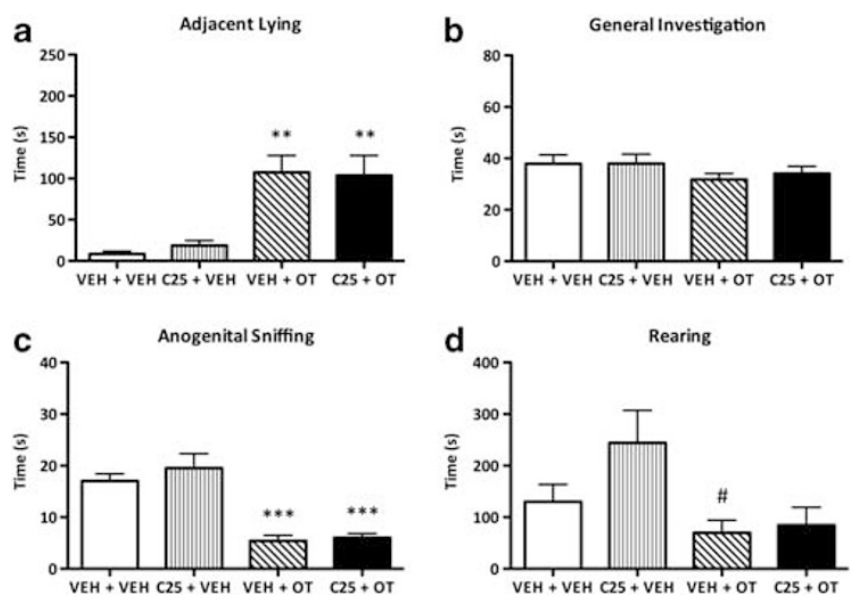

Figure 2 The effects of compound 25 (C25) on oxytocin (OT)-induced social behaviors. The pretreatment with C25 did not affect OT-induced adjacent lying (a), or the decreased anogenital sniffing (c) and rearing (d) induced by OT. General investigation (b) was unaffected. Data are means + SEM, VEH, vehicle, ${ }^{\#} P<0.05$ vs $C 25+V E H,{ }^{*} * P<0.01$ vs VEH + $\mathrm{VEH}$ and $\mathrm{C} 25+\mathrm{VEH}$, and ${ }^{*} * * P<0.00 I$ vs $\mathrm{VEH}+\mathrm{VEH}$ and $\mathrm{C} 25+\mathrm{VEH}$.
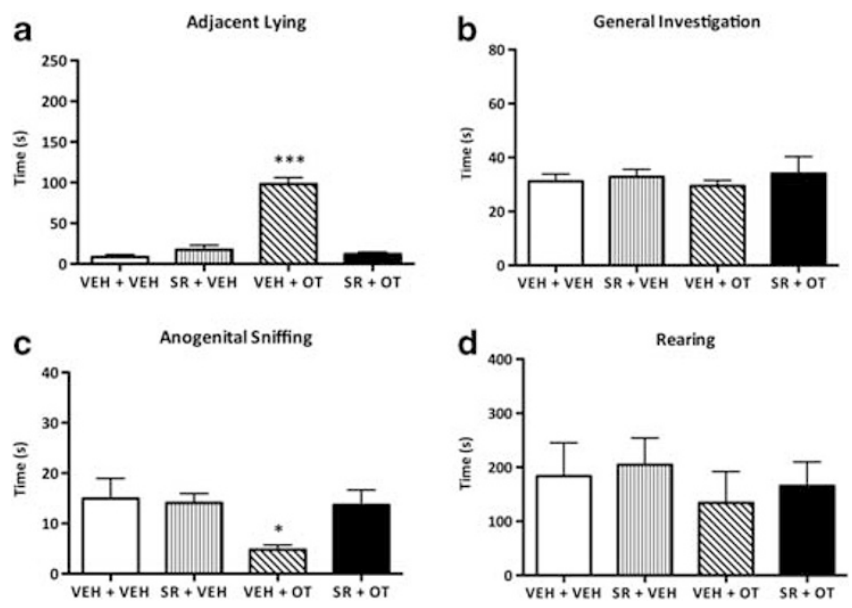

Figure 3 The effects of SR49059 (SR) on oxytocin (OT)-induced social behaviors. Increased adjacent lying (a) caused by OT was completely prevented by pretreatment with SR, while suppression of anogenital sniffing (c) by OT was also prevented. There was no significant effect of treatment on general investigation (b) or rearing (d). Data are means + SEM, VEH, vehicle, $* P<0.05$ vs all other conditions, $* * * P<0.00$ I vs all other conditions.

of treatment on adjacent lying $(\mathrm{F}(3,12)=67.04, P<0.001$; Figure 3a) and anogenital sniffing $(\mathrm{F}(3,12)=5.68, P<0.05$; Figure 3c). Post-hoc tests showed that adjacent lying was significantly increased, whereas anogenital sniffing was reduced, by $0.5 \mathrm{mg} / \mathrm{kg}$ OT relative to all other conditions (adjacent lying: all $P<0.001$; anogenital sniffing: all $P<0.05)$. There was no significant effect of treatment on general investigation $(P>0.05$; Figure $3 \mathrm{~b})$ or rearing behavior $(P>0.05$; Figure $3 \mathrm{~d})$.

\section{Dose-Dependent Effects of AVP on Social Interaction}

The dose-response profile of AVP in the social interaction test is presented in Figure 4. AVP had a significant overall effect on adjacent lying $(\mathrm{F}(4,45)=19.22, \quad P<0.001$;
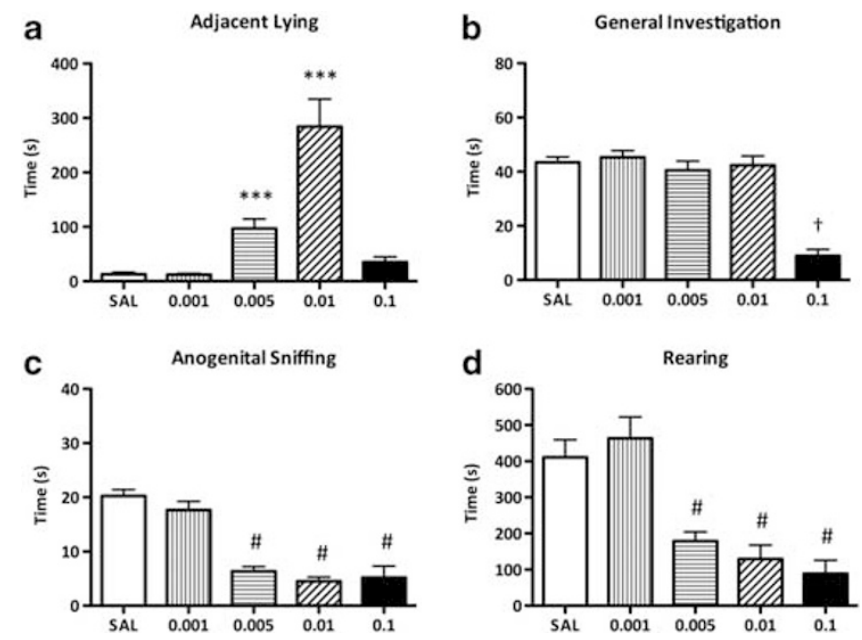

Figure 4 Dose-dependent effects of vasopressin (AVP) on social interaction. (a) Adjacent lying increased in rats given 0.005 and $0.01 \mathrm{mg} /$ $\mathrm{kg}$ AVP. (b) A high dose of AVP $(0.1 \mathrm{mg} / \mathrm{kg})$ resulted in decreased general investigation compared with all other conditions. AVP given at 0.005, 0.0 I, and $0.1 \mathrm{mg} / \mathrm{kg}$ reduced anogenital sniffing (c) and rearing (d) compared with saline $(\mathrm{SAL})$ and $0.001 \mathrm{mg} / \mathrm{kg}$ AVP. Data are means $+\mathrm{SEM},{ }^{\#} P<0.01 \mathrm{vs}$ saline and $0.00 \mathrm{Img} / \mathrm{kg}$ AVP, $* * * * P \leqslant 0.00 \mathrm{I}$ vs saline, $0.00 \mathrm{I}$ and $0.1 \mathrm{mg} / \mathrm{kg}$ AVP, ${ }^{\dagger} P \leqslant 0.00$ I vs all other conditions.

Figure 4a), with post-hoc tests indicating that the 0.01 and $0.005 \mathrm{mg} / \mathrm{kg}$ doses significantly increased adjacent lying compared with all other conditions (all $P \leqslant 0.001$ ), but did not differ significantly from each other $(P>0.05)$ (see Supplementary Video). There was a significant effect of AVP on general investigation $(\mathrm{F}(4,45)=29.97, P<0.001$; Figure $4 \mathrm{~b}$ ), with the $0.1 \mathrm{mg} / \mathrm{kg}$ dose reducing the amount of investigation time relative to all other conditions (all $P<0.001$ ). Moreover, AVP had a significant effect on anogenital sniffing (Kruskal-Wallis test; $\chi^{2}=33.85$, $P<0.001, \mathrm{df}=4$; Figure $4 \mathrm{c}$ ), with $0.005,0.01$, and $0.1 \mathrm{mg} /$ $\mathrm{kg}$ AVP significantly reducing the time spent engaged in this behavior relative to saline treatment (all $P<0.001$ ) and $0.001 \mathrm{mg} / \mathrm{kg}$ AVP (all $P<0.01$ ). Rearing behavior was also significantly reduced by AVP (Kruskal-Wallis test; $\chi^{2}=28.86, P<0.01, \mathrm{df}=4$; Figure $4 \mathrm{~d}$ ) at a dose of 0.005 , 0.01 , and $0.1 \mathrm{mg} / \mathrm{kg}$ relative to saline treatment (all $P<0.01$ ) and $0.001 \mathrm{mg} / \mathrm{kg}$ AVP (all $P<0.01$ ).

\section{Effects of SR49059 on AVP-Induced Social Behavior}

The effects of SR49059 on AVP-induced social interaction are presented in Figure 5. There was a significant overall effect of drug treatment on adjacent lying $(\mathrm{F}(3,12)=22.45$, $P<0.001$; Figure 5a), anogenital sniffing $(\mathrm{F}(3,12)=22.55$, $P<0.001$; Figure $5 \mathrm{c})$, and rearing $(\mathrm{F}(3,12)=5.25, P<0.05$; Figure 5d). Post-hoc tests showed that adjacent lying was significantly increased, whereas anogenital sniffing was reduced, by $0.01 \mathrm{mg} / \mathrm{kg}$ AVP relative to all other conditions (adjacent lying: all $P \leqslant 0.001$; anogenital sniffing: all $P<0.001)$. Pretreatment with SR49059 prevented the reduction in rearing caused by AVP $(P<0.05)$. There was no significant effect of drug treatment on general investigation $(P>0.05$; Figure $5 b)$. 


\section{Prosocial Effects of MDMA}

Rats given MDMA ( $5 \mathrm{mg} / \mathrm{kg}$ ) spent significantly more time engaged in adjacent lying behavior in a 10 -min test than saline-treated rats, $(t(14)=9.42, P<0.001$; see Figure 6 and Supplementary Video), and displayed less anogenital sniffing $(t(14)=5.25, P<0.001)$ and rearing $(t(14)=12.22$, $P<0.001)$. MDMA had no significant effect on general investigation $(P>0.05)$.

\section{Effects of SR49059 on MDMA-Induced Social Behavior}

The interaction of SR49059 with MDMA is shown in Figure 7. Pretreatment with SR49059 prevented the increase
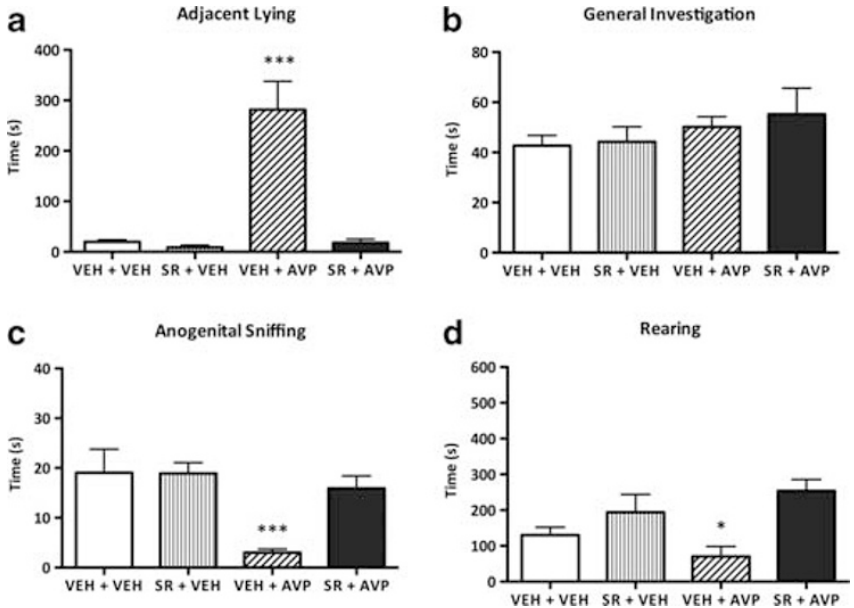

Figure 5 The effects of SR49059 (SR) on vasopressin (AVP)-induced social behaviors. SR prevented AVP-induced adjacent lying (a) and the decrease in anogenital sniffing (c) and rearing (d) caused by AVP. There was no significant effect of drug treatment on general investigation (b). Data are means + SEM, VEH, vehicle, ${ }^{*} P<0.05$ vs SR + AVP condition, ${ }^{*} * * P \leqslant 0.00$ I vs all other conditions. in adjacent lying caused by MDMA, $(t(14)=3.01, P<0.01)$, and the MDMA-induced reduction in anogenital sniffing $(t(14)=2.44, P<0.05)$. However, it did not prevent the MDMA effects on rearing behavior $(P>0.05)$. Rats given SR49059 before MDMA engaged in more general investigation than those given MDMA alone, $(t(14)=5.50, P<0.001)$

\section{Prosocial Effects of Combined Sub-Threshold Doses of OT and MDMA}

Results are shown in Figure 8. Adjacent lying behavior was significantly affected by drug treatment $(\mathrm{F}(3,12)=12.53$, $P \leqslant 0.001$; Figure $8 \mathrm{a}$ ), with post-hoc tests indicating that rats given combined OT and MDMA showed more adjacent lying than those in all other conditions (all $P<0.01$ ). Drug treatment significantly affected anogenital sniffing $(\mathrm{F}(3,12)=8.42, P<0.01$; Figure $8 \mathrm{c})$ and rearing behavior $(\mathrm{F}(3,12)=6.15, P<0.01$; Figure $8 \mathrm{~d})$, with post-hoc tests showing that rats administered combined OT and MDMA spent significantly less time engaged in these behaviors relative to all other groups (anogenital: $P<0.05 v s$ OT, $P<0.01$ vs saline and MDMA; rearing: all $P<0.05)$. There was no significant effect of drug treatment on general investigation $(P>0.05$; Figure $8 \mathrm{~b})$.

\section{Prosocial Effects of Combined Sub-Threshold Doses of AVP and MDMA}

Results are shown in Figure 9. Adjacent lying behavior was significantly affected by drug treatment $(\mathrm{F}(3,12)=16.32$, $P \leqslant 0.001$; Figure 9a), with post-hoc tests revealing that combined AVP and MDMA significantly increased adjacent lying relative to all other treatment conditions (all $P \leqslant 0.001)$. Drug treatment significantly affected anogenital sniffing $(\mathrm{F}(3,12)=20.15, P<0.001$; Figure $9 \mathrm{c})$, with post-hoc tests showing that rats administered AVP, MDMA or the combination of AVP and MDMA, spent significantly less
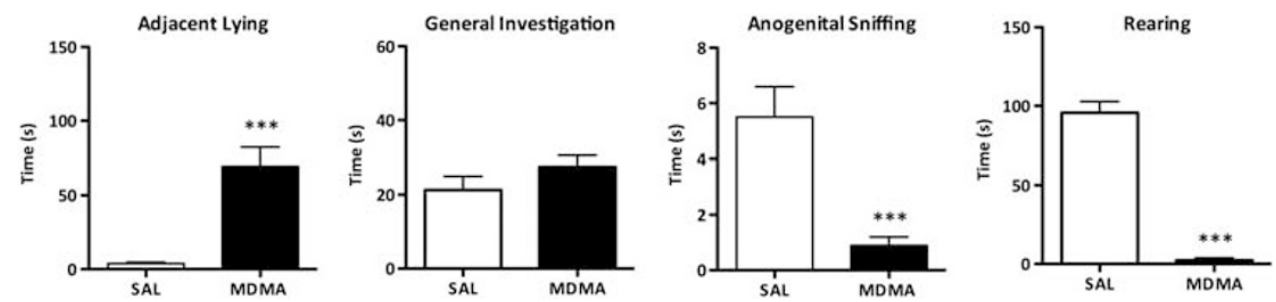

Figure 6 The effects of 3,4-methylenedioxymethamphetamine (MDMA) on social interaction. Rats given MDMA showed a significant increase in adjacent lying as well as a decrease in anogenital sniffing and rearing behavior. Data are means $+\mathrm{SEM}$, $* * * P<0.00$ I vs saline (SAL) animals.
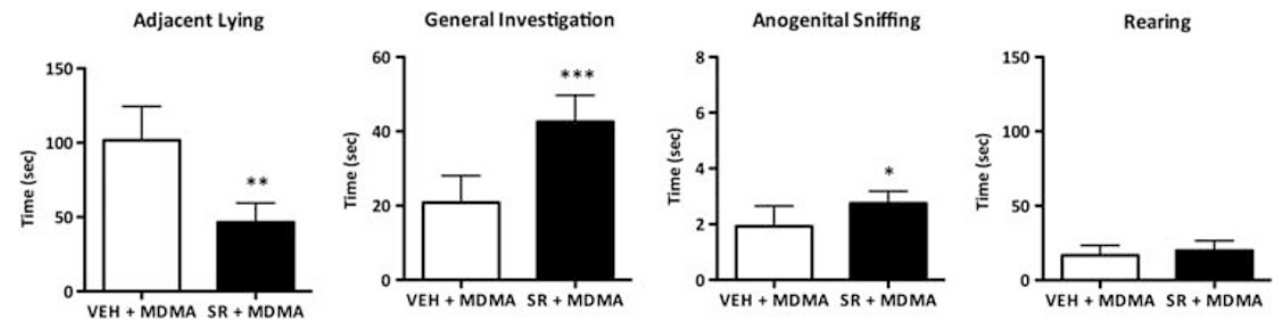

Figure 7 The effects of SR49059 (SR) on 3,4-methylenedioxymethamphetamine (MDMA)-induced social behaviors. Pretreatment with SR reduced MDMA-induced adjacent lying, and attenuated MDMA effects on general investigation and anogenital sniffing. Data are means + SEM, VEH, vehicle, $* P<0.05$ vs $\mathrm{VEH}+\mathrm{MDMA}$, ** $P<0.01$ vs $\mathrm{VEH}+\mathrm{MDMA}$, $* * * P<0.001$ vs $\mathrm{VEH}+\mathrm{MDMA}$. 

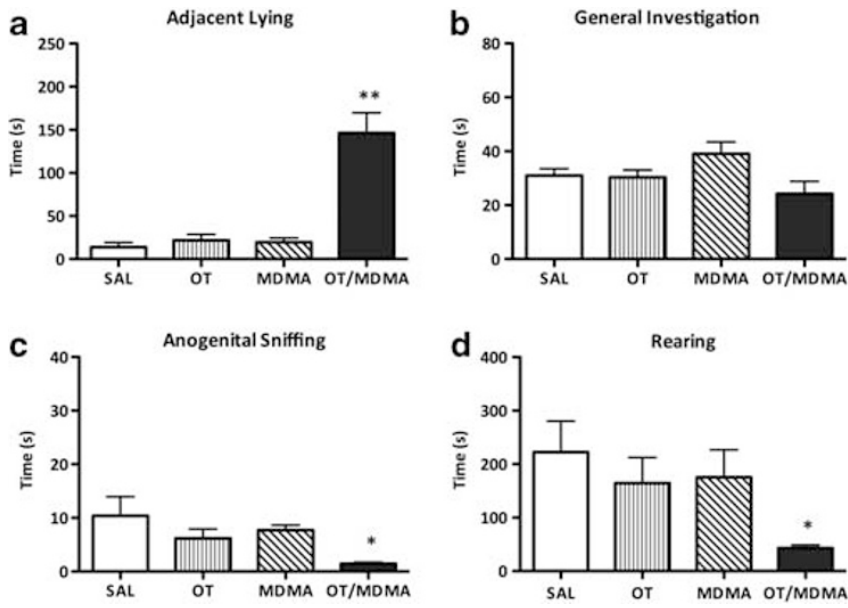

Figure 8 Effects of combined sub-threshold doses of oxytocin (OT) and 3,4-methylenedioxymethamphetamine (MDMA) on social behavior. (a) Rats given OT $(0.25 \mathrm{mg} / \mathrm{kg})$ and MDMA $(2.5 \mathrm{mg} / \mathrm{kg})$ spent significantly longer lying adjacent to each other, and significantly less time engaged in anogenital sniffing (c) and rearing (d) relative to all other conditions. General investigation was unaffected by drug treatment (d). Data are means + SEM, SAL, saline, $* P<0.05$ vs all other conditions, $* * P<0.0$ I vs all other conditions.
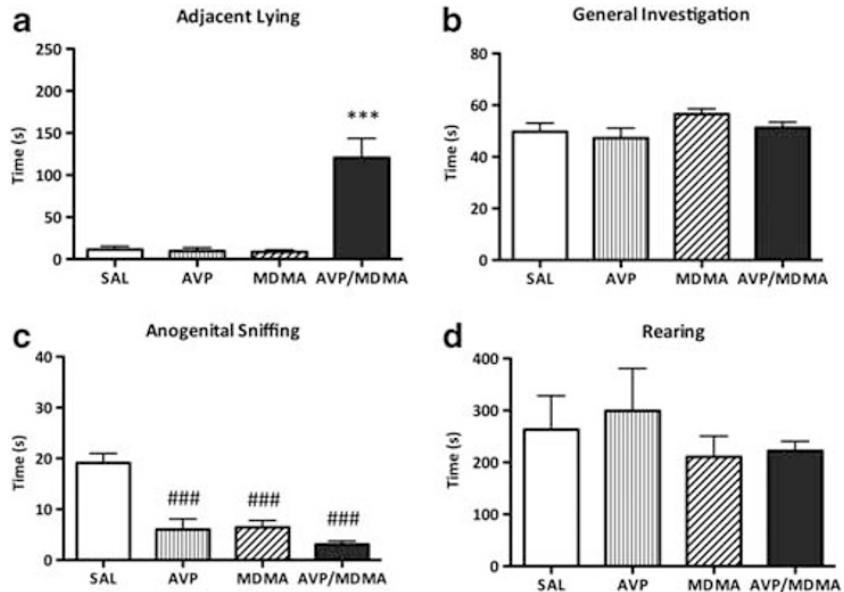

Figure 9 Effects of combined sub-threshold doses of vasopressin (AVP) and 3,4-methylenedioxymethamphetamine (MDMA) on social behavior. (a) Rats administered AVP $(0.025 \mathrm{mg} / \mathrm{kg})$ and MDMA $(2.5 \mathrm{mg} / \mathrm{kg})$ spent significantly longer lying adjacent to each other, and significantly less time engaged in anogenital sniffing (c). There was no significant effect of treatment on general investigation (b) or rearing (d). Data are means + SEM, $* * * * \leqslant 0.001$ vs all other conditions, ${ }^{\# \# \#} P \leqslant 0.00$ I vs saline (SAL)

time engaged in this behavior relative to saline (all $P \leqslant 0.001)$. There was no significant treatment effect on general investigation $(P>0.05 ;$ Figure $9 b)$ or rearing $(P>0.05$; Figure 9d).

\section{DISCUSSION}

The present study examined the prosocial effects of OT, AVP and MDMA and their combinations in the social interaction paradigm in Long-Evans rats. A principal aim was to assess whether robust prosocial effects of peripherally administered OT and AVP could be obtained, and a further aim was to compare this with previously demon- strated MDMA prosocial effects in rats. We also studied the possible involvement of the OTR and $\mathrm{V} 1_{\mathrm{A}} \mathrm{R}$ in mediating the prosocial effects of OT, AVP and MDMA.

Up until this point, prosocial effects of OT in rodent models have only been demonstrated with chronic intracranial administration (Insel and Winslow, 1991), or as a lasting residual effect of repeated peripheral (Bowen et al, 2011) or intracranial (Witt et al, 1992) OT administration, or in the 'rescue' of stressed animals that are socially phobic (Slattery and Neumann, 2010), socially defeated (Lukas et al, 2011), or socially stressed due to isolation (Grippo et al, 2009). Here, we show that acute peripheral injection of OT robustly increased the prosocial behavior of adjacent lying in Long-Evans rats under normal basal conditions. A narrow dose window was evident in which these effects were observed, with $0.5 \mathrm{mg} / \mathrm{kg}$ OT but not $0.1,0.25$ or $1 \mathrm{mg} / \mathrm{kg}$ increasing adjacent lying. The behavior of adjacent lying has been previously described in Wistar rats administered MDMA, or the 5- $\mathrm{HT}_{1 \mathrm{~A}}$ receptor agonist 8-OH-DPAT (Thompson et al, 2007; Thompson et al, 2009). This MDMA effect was replicated here in Long-Evans rats.

We also show here for the first time that AVP, like OT, induces adjacent lying in rats. A robust increase was observed at $0.01 \mathrm{mg} / \mathrm{kg}$ AVP and $0.005 \mathrm{mg} / \mathrm{kg}$ AVP in comparison with the other doses, which had no such effects. OT and AVP are sometimes conceptualized as having opposing influences, with mutually inhibitory effects evident in the amygdala (Huber et al, 2005), and OT is generally linked to passive prosocial behaviors while AVP is more linked to fear and aggression (Debiec, 2005). It is somewhat surprising then that AVP should have such clear prosocial effects in rats, mimicking those of OT. Up until this point, few studies have examined the behavioral effects of IP AVP administration. One study found that rats showed a decrease in anxiety-like behavior on the elevated plus maze (Appenrodt et al, 1998), while several studies focused on avoidance behavior and AVP's ability to delay extinction (Bohus et al, 1972; Koob et al, 1981). Intracranial administration of AVP facilitates social memory and recognition in rats (Le Moal et al, 1987), and it helps form partner preference as well as mediates selective aggression in prairie voles (Winslow, 1993).

The commonality of effects of OT and AVP was also evident not only in adjacent lying, but also in both OT $(0.5 \mathrm{mg} / \mathrm{kg})$ and AVP $(0.01 \mathrm{mg} / \mathrm{kg})$ significantly reducing anogenital sniffing. Anogenital sniffing is an important behavior for conspecific recognition, and its reduction by OT and AVP may relate to a modulation of normal social recognition processes, whereby unfamiliar rats are in some way more rapidly accepted as familiar. Indeed, the infusion of AVP or OT into the olfactory bulb can improve social recognition in male rats, while administration of a $V 1_{A} R$ antagonist disrupts social recognition processes (Dluzen et al, 1998; Tobin et al, 2010). Similarly, in mice, sitespecific administration of an OTR antagonist into the medial amygdala results in diminished social recognition (Ferguson et al, 2001). It is possible, then, that an enhancement of social recognition by OT and AVP may be related to the reduced anogenital sniffing observed in the current study.

It is important to consider whether the apparently prosocial effects of OT and AVP reflected in increased 
Table I Drug Effects on Behavior in the Social Interaction Test (Values are Means)

\begin{tabular}{|c|c|c|c|c|c|c|c|c|c|}
\hline Behavior & $\begin{array}{c}\text { SAL }^{\mathrm{a}} \\
(n=8)\end{array}$ & $\begin{array}{c}\text { OT } \\
(n=8)\end{array}$ & $\begin{array}{c}\text { AVP } \\
(n=10)\end{array}$ & $\begin{array}{l}\text { MDMA }^{b} \\
(n=8)\end{array}$ & $\begin{array}{c}\text { OT + MDMA } \\
(n=4)\end{array}$ & $\begin{array}{c}A V P+\text { MDMA } \\
(n=4)\end{array}$ & $\begin{array}{c}\mathrm{SR}+\mathrm{OT} \\
(n=4)\end{array}$ & $\begin{array}{c}\mathrm{SR}+\mathrm{AVP} \\
(n=4)\end{array}$ & $\begin{array}{c}\text { SR }+ \text { MDMA } \\
(n=8)\end{array}$ \\
\hline Adjacent lying (s) & 11.55 & 167.08 & 284.08 & 69.52 & 146.25 & 120.43 & 11.75 & 17.7 & 46.38 \\
\hline Anogenital sniffing (s) & 16.44 & 11.27 & 4.5 & 0.89 & 1.43 & 3.1 & 13.67 & 15.9 & 2.75 \\
\hline Rearing (s) & 213.07 & 109.11 & 129.42 & 2.23 & 43 & 222.2 & 165.42 & 253.83 & 19.9 \\
\hline
\end{tabular}

${ }^{a}$ alues are an average of means from saline and vehicle conditions from all experiments.

${ }^{\mathrm{b}}$ This was a 10-min test, all other tests were of $30 \mathrm{~min}$ in duration.

adjacent lying and decreased anogenital sniffing may reflect a non-specific sedative effect. Higher peripheral doses of OT (Hicks et al, 2012) and AVP (Andrews et al, 1983; Ettenberg et al, 1983) in rats can reduce locomotor activity. Several factors are worth noting here. First, it was clear that the highest doses of AVP $(0.1 \mathrm{mg} / \mathrm{kg})$ and OT $(1 \mathrm{mg} / \mathrm{kg})$ used had inhibitory effects on ongoing activity, yet these doses did not increase adjacent lying. Rather it was at intermediate doses, where general investigation was not affected, that increased adjacent lying was seen with both OT and AVP. As the summary in Table 1 shows the critical doses that increased adjacent lying and decreased anogenital sniffing were without effect on general investigation and had only marginally inhibitory effects on rearing, it is also important to note that MDMA given to individual rats tends to produce hyperactivity, rather than sedation, yet in the current study, and our previous studies MDMA also increases adjacent lying and decreases anogenital sniffing and rearing (Thompson et al, 2007; Thompson et al, 2009).

The striking similarity between OT, AVP and MDMA in these effects suggests a commonality of action, and this was confirmed in Experiments 8 and 9 where two drugs (OT and MDMA or AVP and MDMA) combined in low doses, produced the characteristic effects of either drug given alone (Table 1). Interestingly, the characteristic changes in adjacent lying and anogenital sniffing produced by MDMA, AVP and OT were reversed by pretreatment with SR49059, which by itself had no significant effects on social behavior. Moreover, the selective OTR antagonist C25 (Brown et al, 2010) had no effects on OT-induced social behaviors, suggesting that the effects of OT, AVP and MDMA are not mediated by the OTR. It is important to note that we have previously found intracranial administration of the nonselective OTR antagonist tocinoic acid reduced the prosocial effects of MDMA (Thompson et al, 2007). However, this may be due to non-specific blockade of AVP receptors given the high dose used (ie, $20 \mu \mathrm{g} / \mu \mathrm{l}$ ) and the functional activity of this ligand at both OT and AVP receptors (Maggi et al, 1987). Therefore, our current findings indicate that OT and AVP may directly act on the $\mathrm{V} 1_{\mathrm{A}} \mathrm{R}$ to produce prosocial effects, while MDMA may indirectly stimulate the $\mathrm{V} 1_{\mathrm{A}} \mathrm{R}$ through serotonin-induced OT and/or AVP release in the hypothalamus (Jorgensen et al, 2003).

SR49059 has only weak affinity for the OTR (Manning et al, 2012) and when given intravenously at the current dose of $1 \mathrm{mg} / \mathrm{kg}$ inhibits AVP-induced hypertension, while exhibiting no agonist or antagonist effects at other peptide ligand receptors (Manning et al, 2012). Thus, the increase in sociability seen with AVP, OT and MDMA may be independent of direct OTR activation. However, close inspection of Figures 3, 5 and 7 suggests that SR49059 completely reverses OT- and AVP-induced increases in adjacent lying, but only partially blocks the increase caused by MDMA. Therefore, the possibility of MDMA acting to promote sociability through other mechanisms cannot be ruled out. Experiments using OTR or $\mathrm{V} 1_{\mathrm{A}}$ receptor null mice might be particularly instructive.

One limitation of the current study is the extent to which the antagonists C25 and SR49059 can cross the BBB. Limited in vivo findings with C25 (Brown et al, 2010) have been reported; however, the compound has excellent bioavailability and aqueous solubility. A previous report suggests that SR49059 administered intravenously is not able to penetrate the BBB when dissolved in a $0.6 \%$ methylcellulose and saline vehicle (Tribollet et al, 1999). However, other studies suggest that a DMSO vehicle may increase the permeability of the BBB and carry along other dissolved substances (Jacob and Wood, 1967). Certainly, the fact that the social effects of MDMA were largely prevented by SR49059 in the present study strongly argues for its effectiveness at central sites.

The present results also add to mounting evidence that peripherally administered OT and/or AVP can have important behavioral effects in rodent models. Although it might be argued that these effects occur indirectly via vagal afferents, the evidence for direct penetration of the central nervous system is increasingly convincing. Peripherally administered OT has a wide variety of behavioral effects in rodents including decreased anxiety in adulthood in rats (Bowen et al, 2011), and increased social behavior in male prairie voles (Bales et al, 2012). Pretreatment with peripheral OT dose-dependently blocks disruption of prepulse inhibition seen in rats administered amphetamine and dizolcilpine, suggesting that OT can directly modulate dopamine and glutamate systems in the brain (Feifel and Reza, 1999). Peripheral OT also increases c-Fos expression in a region-specific manner, with activated areas including the paraventricular nucleus of the hypothalamus and the supraoptic nucleus, both of which contain high levels of OT neurons (Hicks et al, 2012). Moreover, the pattern of c-Fos expression seen with peripheral OT injections strongly resembles that seen with ICV OT, or with non-peptide OT agonists such as WAY 267,464 that readily penetrate the brain (Hicks et al, 2012). Furthermore, behavioral changes, such as, increased punished crossings in the four-plate anxiolytic activity test caused by peripheral OT, can be 
blocked with central administration of an OTR antagonist, suggesting central actions of peripheral OT (Ring et al, 2006).

Overall, our results with SR49059 imply that the prosocial effects induced by OT, AVP, and MDMA are mediated by brain AVP systems. This is consistent with previous observations that exogenous AVP prolongs social memory (Le Moal et al, 1987), improves social recognition in rats (Engelmann and Landgraf, 1994), and facilitates pair bonding in male Prairie voles (Insel et al, 1998). As noted above, MDMA has been reported to increase AVP plasma levels in humans (Henry et al, 1998) and stimulate AVP release in isolated rat hypothalamus (Fallon et al, 2002).

Perhaps the most striking finding, however, in the current study, was that the combination of sub-threshold doses of these drugs (doses that by themselves did not affect social behavior) induced a robust increase in adjacent lying. The combination of these drugs also resulted in reduced anogenital sniffing and decreased rearing. This finding is consistent with a recent study showing that OT partially substitutes for MDMA in a drug discrimination paradigm, indicating an overlap of the subjective effects of the two drugs (Broadbear et al, 2011). There is current interest in the utility of MDMA in treating post-traumatic stress disorder (PTSD) (Mithoefer et al, 2011). However, animal models suggest that repeated MDMA can perturb brain neurochemistry and increase vulnerability to depression and anxiety-like behaviors, even after prolonged cessation of use (McGregor et al, 2003). Based on our findings that the combination of sub-threshold doses of OT and MDMA, and AVP and MDMA, have positive effects on social behavior, treatment for PTSD could potentially be made safer by lowering the dose of MDMA and adding OT or AVP, thereby reducing the likelihood that these patients develop adverse effects with long-term treatment.

In summary, our study provides the first demonstration of acute prosocial effects of peripherally administered OT and AVP in rats, similar to that previously reported with MDMA. The adjacent lying induced by OT is unaffected by $\mathrm{C} 25$, however, SR49059 reversed the prosocial effects induced by OT, AVP, and MDMA providing support for a common mechanism of action involving the $\mathrm{V} 1_{\mathrm{A}} \mathrm{R}$. These findings may be useful in the development of therapeutics for social disorders by allowing them to target the $\mathrm{V} 1_{\mathrm{A}}$ receptor. This study also shows that co-administration of sub-threshold doses of these drugs stimulates prosocial behavior that further indicates a commonality of action between them. This observation may be of utility in clinical settings where use of MDMA is being contemplated for therapeutic purposes.

\section{FUNDING AND DISCLOSURE}

The authors declare no conflict of interest.

\section{ACKNOWLEDGEMENTS}

Research was supported by a National Health and Medical Research Council Grants 1033444 and 1011518. Linnet Ramos is the recipient of a University of Sydney World Scholars Award. ISM is supported by an Australian Professorial Fellowship from the Australian Research Council.

\section{REFERENCES}

Ando RD, Benko A, Ferrington L, Kirilly E, Kelly PAT, Bagdy G (2006). Partial lesion of the serotonergic system by a single dose of MDMA results in behavioural disinhibition and enhances acute MDMA-induced social behaviour on the social interaction test. Neuropharmacology 50: 884-896.

Andrews J, Newton B, Sahgal A (1983). The effects of vasopressin on positively rewarded responding and on locomotor activity in rats. Neuropeptides 4: 17-29.

Appenrodt E, Schnabel R, Schwarzberg H (1998). Vasopressin administration modulates anxiety-related behavior in rats. Physiol Behav 64: 543-547.

Bales KL, Perkeybile AM, Conley OG, Lee MH, Guoynes CD, Downing GM et al (2012). Chronic intranasal oxytocin causes long-term impairments in partner preference formation in male prairie voles. Biol Psychiatr; e-pub ahead of print 16 October 2012; doi:10.1016/biopsych.2012.08.025.

Baumgartner T, Heinrichs M, Vonlanthen A, Fischbacher U, Fehr E (2008). Oxytocin shapes the neural circuitry of trust and trust adaptation in humans. Neuron 58: 639-650.

Bielsky IF, Hu S-B, Ren X, Terwilliger EF, Young LJ (2005). The V1a vasopressin receptor is necessary and sufficient for normal social recognition: a gene replacement study. Neuron 47: 503-513.

Bielsky IF, Hu SB, Szegda KL, Westphal H, Young LJ (2004). Profound impairment in social recognition and reduction in anxiety-like behavior in vasopressin V1a receptor knockout mice. Neuropsychopharmacology 29: 483-493.

Bohus B, Ader R, De Wied D (1972). Effects of vasopressin on active and passive avoidance behavior. Horm Behav 3: 191-197.

Bowen MT, Carson DS, Spiro A, Arnold JC, McGregor IS (2011). Adolescent oxytocin exposure causes persistent reductions in anxiety and alcohol consumption and enhances sociability in rats. PLoS One 6: e27237.

Broadbear JH, Tunstall B, Beringer K (2011). Examining the role of oxytocin in the interoceptive effects of 3, 4-methylenedioxymethamphetamine (MDMA, "Ecstacy") using a drug discrimination paradigm in the rat. Addict Biol 16: 202-214.

Brown A, Brown TB, Calabrese A, Ellis D, Puhalo N, Ralph $\mathrm{M}$ et al (2010). Triazole oxytocin antagonists: identification of an aryloxyazetidine replacement for a biaryl substituent. Bioorg Med Chem Lett 20: 516-520.

Caldwell HK, Lee HJ, Macbeth AH, Young WS 3rd (2008). Vasopressin: behavioral roles of an "original" neuropeptide. Prog Neurobiol 84: 1-24.

Capurro A, Reyes-Parada M, Olazabal D, Perrone R, Silveira R, Macadar O (1997). Aggressive behavior and jamming avoidance response in the weakly electric fish Gymnotus carapo: effects of 3, 4-methylenedioxymethamphetamine (MDMA). Comp Biochem Physiol A 118: 831-840.

Dantzer R, Koob GF, Le Moal M (1988). Septal vasopressin modulates social memory in male rats. Brain Res 457: 143-147.

Debiec J (2005). Peptides of love and fear: vasopressin and oxytocin modulate the integration of information in the amygdala. Bioessays 27: 869-873.

Dluzen DE, Muraoka S, Engelmann M, Landgraf R (1998). The effects of infusion of arginine vasopressin, oxytocin, or their antagonists into the olfactory bulb upon social recognition responses in male rats. Peptides 19: 999-1005.

Domes G, Heinrichs M, Michel A, Berger C, Herpertz SC (2007). Oxytocin improves "mind-reading" in humans. Biol Psychiatr 61: 731-733.

Dumont G, Sweep F, van der Steen R, Hermsen R, Donders A, Touw D et al (2009). Increased oxytocin concentrations and prosocial feelings in humans after ecstasy (3, 4-methylenedioxymethamphetamine) administration. Soc Neurosci 4: 359-366. 
Dumont G, Verkes R (2006). A review of acute effects of 3 , 4-methylenedioxymethamphetamine in healthy volunteers. J Psychopharmacol 20: 176-187.

Egashira N, Tanoue A, Matsuda T, Koushi E, Harada S, Takano Y et al (2007). Impaired social interaction and reduced anxietyrelated behavior in vasopressin V1a receptor knockout mice. Behav Brain Res 178: 123-127.

Engelmann M, Landgraf R (1994). Microdialysis administration of vasopressin into the septum improves social recognition in Brattleboro rats. Physiol Behav 55: 145-149.

Engelmann M, Ludwig M, Landgraf R (2006). Simultaneous monitoring of intracerebral release and behavior: endogenous vasopressin improves social recognition. J Neuroendocrinol 6: 391-395.

Ettenberg A, van der Kooy D, Le Moal M, Koob GF, Bloom FE (1983). Can aversive properties of (peripherally-injected) vasopressin account for its putative role in memory? Behav Brain Res 7: 331-350.

Fallon J, Shah D, Kicman A, Hutt A, Henry J, Cowan D et al (2002). Action of MDMA (ecstasy) and its metabolites on arginine vasopressin release. Ann NY Acad Sci 965: 399-409.

Feifel D, MacDonald K, Cobb P, Minassian A (2012). Adjunctive intranasal oxytocin improves verbal memory in people with schizophrenia. Schizophr Res 139: 207-210.

Feifel D, Reza T (1999). Oxytocin modulates psychotomimetic-induced deficits in sensorimotor gating. Psychopharmacology 141: 93-98.

Ferguson JN, Aldag JM, Insel TR, Young LJ (2001). Oxytocin in the medial amygdala is essential for social recognition in the mouse. J Neurosci 21: 8278-8285.

File SE (1980). The use of social interaction as a method for detecting anxiolytic activity of chlordiazepoxide-like drugs. J Neurosci Methods 2: 219-238.

File SE, Pope J (1974). Social interaction between drugged and undrugged rats. Learn Behav 2: 161-164.

Grippo AJ, Trahanas DM, Zimmerman RR 2nd, Porges SW, Carter CS (2009). Oxytocin protects against negative behavioral and autonomic consequences of long-term social isolation. Psychoneuroendocrinology 34: 1542-1553.

Guastella AJ, Howard AL, Dadds MR, Mitchell P, Carson DS (2009). A randomized controlled trial of intranasal oxytocin as an adjunct to exposure therapy for social anxiety disorder. Psychoneuroendocrinology 34: 917-923.

Henry JA, Fallon JK, Kicman AT, Hutt AJ, Cowan DA, Forsling M (1998). Low-dose MDMA ("Ecstasy") induces vasopressin secretion. Lancet 351: 1784.

Hicks C, Jorgensen W, Brown C, Fardell J, Koehbach J, Gruber CW et al (2012). The nonpeptide oxytocin receptor agonist WAY 267,464: receptor-binding profile, prosocial effects and distribution of c-Fos expression in adolescent rats. J Neuroendocrinol 24: 1012-1029.

Hollander E, Bartz J, Chaplin W, Phillips A, Sumner J, Soorya L et al (2007). Oxytocin increases retention of social cognition in autism. Biol Psychiatr 61: 498-503.

Huber D, Veinante P, Stoop R (2005). Vasopressin and oxytocin excite distinct neuronal populations in the central amygdala. Science 308: 245-248.

Humphreys AP, Einon DF (1981). Play as a reinforcer for mazelearning in juvenile rats. Anim Behav 29: 259-270.

Hunt GE, McGregor IS, Cornish JL, Callaghan PD (2011). MDMAinduced c-Fos expression in oxytocin-containing neurons is blocked by pretreatment with the 5-HT-1A receptor antagonist WAY 100635. Brain Res Bull 86: 65-73.

Insel TR, Winslow JT (1991). Central administration of oxytocin modulates the infant rat's response to social isolation. Eur $J$ Pharmacol 203: 149-152.

Insel TR, Winslow JT, Wang Z, Young LJ (1998). Oxytocin, vasopressin, and the neuroendocrine basis of pair bond formation. Adv Exp Med Biol 449: 215-224.
Jacob SW, Wood DC (1967). Dimethyl sulfoxide (DMSO) toxicology, pharmacology, and clinical experience. Am J Surg 114: 414-426.

Jorgensen H, Riis M, Knigge U, Kjaer A, Warberg J (2003). Serotonin receptors involved in vasopressin and oxytocin secretion. J Neuroendocrinol 15: 242-249.

Kelly AM, Kingsbury MA, Hoffbuhr K, Schrock SE, Waxman B, Kabelik D et al (2011). Vasotocin neurons and septal V1a-like receptors potently modulate songbird flocking and responses to novelty. Horm Behav 60: 12-21.

Koob GF, Le Moal M, Gaffori O, Manning M, Sawyer WH, Rivier J et al (1981). Arginine vasopressin and a vasopressin antagonist peptide: opposite effects on extinction of active avoidance in rats. Regul Pept 2: 153-163.

Kosfeld M, Heinrichs M, Zak PJ, Fischbacher U, Fehr E (2005). Oxytocin increases trust in humans. Nature 435: 673-676.

Latane B, Cappell H, Joy V (1970). Social deprivation, housing density, and gregariousness in rats. J Comp Physiol Psych 70: 221-227.

Le Moal M, Dantzer R, Michaud B, Koob G (1987). Centrally injected arginine vasopressin (AVP) facilitates social memory in rats. Neurosci Lett 77: 353-359.

Lee HJ, Macbeth AH, Pagani JH, Young WS 3rd (2009). Oxytocin: the great facilitator of life. Prog Neurobiol 88: 127-151.

Loyens E, Vermoesen K, Schallier A, Michotte Y, Smolders I (2011). Proconvulsive effects of oxytocin in the generalized pentylenetetrazol mouse model are mediated by vasopressin 1a receptors. Brain Res 1436: 43-50.

Lukas M, Neumann ID (2012). Oxytocin and vasopressin in rodent behaviors related to social dysfunctions in autism spectrum disorders. Behav Brain Res; e-pud ahead of print 17 August 2012; doi:10.1016/j.bbr.2012.08.011.

Lukas M, Toth I, Reber SO, Slattery DA, Veenema AH, Neumann ID (2011). The neuropeptide oxytocin facilitates pro-social behavior and prevents social avoidance in rats and mice. Neuropsychopharmacology 36: 2159-2168.

Maggi M, Malozowski S, Kassis S, Guardabasso V, Rodbard D (1987). Identification and characterization of two classes of receptors for oxytocin and vasopressin in porcine tunica albuginea, epididymis, and vas deferens. Endocrinology 120: 986-994.

Maldonado E, Navarro J (2001). MDMA ('Ecstasy') exhibits an anxiogenic-like activity in social encounters between male mice. Pharmacol Res 44: 27-31.

Manning M, Misicka A, Olma A, Bankowski K, Stoev S, Chini B et al (2012). Oxytocin and vasopressin agonists and antagonists as research tools and potential therapeutics. J Neuroendocrinol 24: 609-628.

Manning M, Stoev S, Chini B, Durroux T, Mouillac B, Guillon G (2008). Peptide and non-peptide agonists and antagonists for the vasopressin and oxytocin $\mathrm{V} 1 \mathrm{a}, \mathrm{V} 1 \mathrm{~b}, \mathrm{~V} 2$ and OT receptors: research tools and potential therapeutic agents. Prog Brain Res 170: 473-512.

McGregor IS, Clemens KJ, Van der Plasse G, Li KM, Hunt GE, Chen $\mathrm{F}$ et al (2003). Increased anxiety 3 months after brief exposure to MDMA ('Ecstasy') in rats: association with altered 5-HT transporter and receptor density. Neuropsychopharmacology 28: $1472-1484$.

Mithoefer MC, Wagner MT, Mithoefer AT, Jerome L, Doblin R (2011). The safety and efficacy of \pm 3 , 4-methylenedioxymethamphetamine-assisted psychotherapy in subjects with chronic, treatment-resistant posttraumatic stress disorder: the first randomized controlled pilot study. J Psychopharmacol 25: 439-452.

Perras B, Droste C, Born J, Fehm HL, Pietrowsky R (1997). Verbal memory after three months of intranasal vasopressin in healthy old humans. Psychoneuroendocrinology 22: 387-396.

Pietrowsky R, Struben C, Molle M, Fehm HL, Born J (1996). Brain potential changes after intranasal vs. intravenous administration 
of vasopressin: evidence for a direct nose-brain pathway for peptide effects in humans. Biol Psychiatry 39: 332-340.

Renner MJ, Rosenzweig MR (2004). Social interactions among rats housed in grouped and enriched conditions. Dev Psychobiol 19: 303-313.

Rex A, Sondern U, Voigt J, Franck S, Fink H (1996). Strain differences in fear-motivated behavior of rats. Pharmacol Biochem Behav 54: 107-111.

Ring RH, Malberg JE, Potestio L, Ping J, Boikess S, Luo B et al (2006). Anxiolytic-like activity of oxytocin in male mice: behavioral and autonomic evidence, therapeutic implications. Psychopharmacology 185: 218-225.

Sala M, Braida D, Lentini D, Busnelli M, Bulgheroni E, Capurro V et al (2011). Pharmacologic rescue of impaired cognitive flexibility, social deficits, increased aggression, and seizure susceptibility in oxytocin receptor null mice: a neurobehavioral model of autism. Biol Psychiatry 69: 875-882.

Schorscher-Petcu A, Sotocinal S, Ciura S, Dupre A, Ritchie J, Sorge RE et al (2010). Oxytocin-induced analgesia and scratching are mediated by the vasopressin-1A receptor in the mouse. J Neurosci 30: 8274-8284.

Simmler LD, Hysek CM, Liechti ME (2011). Sex differences in the effects of MDMA (ecstasy) on plasma copeptin in healthy subjects. J Clin Endocrinol Metab 96: 2844-2850.

Slattery D, Neumann I (2010). Chronic icv oxytocin attenuates the pathological high anxiety state of selectively bred Wistar rats. Neuropharmacology 58: 56-61.

Tachibana M, Kagitani-Shimono K, Mohri I, Yamamoto T, Sanefuji W, Nakamura A et al (2013). Long-term administration of intranasal oxytocin is a safe and promising therapy for early adolescent boys with autism spectrum disorders. J Child Adolesc Psychopharmacol 23: 123-127.
Thompson M, Callaghan P, Hunt G, Cornish J, McGregor I (2007). A role for oxytocin and 5-HT(1A) receptors in the prosocial effects of 3, 4 methylenedioxymethamphetamine ('Ecstasy'). Neuroscience 146: 509-514.

Thompson M, Hunt G, McGregor I (2009). Neural correlates of MDMA ('Ecstasy')-induced social interaction in rats. Soc Neurosci 4: 60-72.

Thompson MR, Callaghan PD, Hunt GE, McGregor IS (2008). Reduced sensitivity to MDMA-induced facilitation of social behaviour in MDMA pre-exposed rats. Prog Neuro-Psychopharmacol Biol Psychiatr 32: 1013-1021.

Thompson RR, George K, Walton JC, Orr SP, Benson J (2006). Sex-specific influences of vasopressin on human social communication. Proc Natl Acad Sci USA 103: 7889-7894.

Thompson RR, Gupta S, Miller K, Mills S, Orr S (2004). The effects of vasopressin on human facial responses related to social communication. Psychoneuroendocrinology 29: 35-48.

Tobin VA, Hashimoto H, Wacker DW, Takayanagi Y, Langnaese K, Caquineau $C$ et al (2010). An intrinsic vasopressin system in the olfactory bulb is involved in social recognition. Nature 464: 413-417.

Tribollet E, Raufaste D, Maffrand JP, Serradeil-Le Gal C (1999). Binding of the non-peptide vasopressin V1A receptor antagonist SR-49059 in the rat brain: an in vitro and in vivo autoradiographic study. Neuroendocrinology 69: 113-120.

Veenema A, Bredewold R, De Vries G (2011). Vasopressin regulates social recognition in juvenile and adult rats of both sexes, but in sex-and age-specific ways. Horm Behav 61: 50-56.

Winslow JT (1993). A role for central vasopressin in pair bonding in monogamous prairie voles. Nature 365: 545-547.

Witt DM, Winslow JT, Insel TR (1992). Enhanced social interactions in rats following chronic, centrally infused oxytocin. Pharmacol Biochem Behav 43: 855-861.

Supplementary Information accompanies the paper on the Neuropsychopharmacology website (http://www.nature.com/npp) 